\title{
DESAIN ULANG DAN ANALISIS RESPONS STRUKTURAL PERKERASAN LENTUR PADA JALAN PANTURA RUAS TANGERANG-SERANG
}

\author{
Jayadi Putra ${ }^{1}$ dan Anissa Noor Tajudin² \\ ${ }^{1}$ Program Studi Sarjana Teknik Sipil, Universitas Tarumanagara, Jl. Letjen S. Parman No.1 Jakarta \\ jayadi.325160116@stu.untar.ac.id \\ ${ }^{2}$ Program Studi Sarjana Teknik Sipil, Universitas Tarumanagara, J1. Letjen S. Parman No.1 Jakarta \\ anissat@ft.untar.ac.id
}

Masuk: 11-01-2021, revisi: 01-02-2021, diterima untuk diterbitkan: 02-02-2021

\begin{abstract}
The highway is a land lanes on the surface of the earth which is made by humans with various sizes, shapes and types of construction so that they can be used to transport the traffic of people, animals, objects and vehicles that transport goods from one place to another practically and fast. Roads that are continuously used can cause damage. Therefore, roads require maintenance per unit time of year. Pantura is the main road on the island of Java which is better known as the National road I, this road network is parallel to the coastline of the island. Then, this route connects national activities between centers. The purpose of this study is to redesign flexible pavement through three methods, namely the 2002, 2013, and 2017 methods, to analyze the structural response of the pavement, and to analyze the damage that occurs on the pavement. In planning the pavement thickness, an effective and efficient method is needed in order to obtain an economical result. Comparison of calculations for the three methods is used. The structural responses reviewed are vertical strain and horizontal strain which can analyze fatigue damage and rutting damage on flexible pavements. The KENPAVE program also assists in the calculation of flexible pavement design and other parameters.
\end{abstract}

Keywords: Pantura Road; flexible pavement; redesign; KENPAVE

\begin{abstract}
ABSTRAK
Jalan raya merupakan jalur - jalur tanah di atas permukaan bumi yang dibuat oleh manusia dengan macam-macam ukuran, bentuk dan jenis konstruksinya sehingga dapat digunakan untuk menyalurkan lalu lintas orang, hewan, benda dan kendaraan yang mengangkut barang dari suatu tempat ke tempat lainnya dengan praktis dan cepat. Jalan yang terus menerus dipakai dapat menyebabkan kerusakan oleh sebab itu, jalan memerlukan pemeliharaan setiap per satuan waktu dalam tahun. Pantura merupakan jalan utama di Pulau Jawa yang lebih dikenal dengan jalan Nasional I, jaringan jalan ini sejajar dengan garis pantai pulau lokasi tersebut. Kemudian, jalur ini menghubungkan kegiatan nasional antarpusat. Tujuan dari penelitian ini adalah mendesain ulang perkerasan lentur melalui ketiga metode yaitu metode 2002, 2013, dan 2017, menganalisis respons struktural perkerasan, dan menganalisis kerusakan yang terjadi pada perkerasan. Dalam merencanakan tebal perkerasan jalan diperlukan metode yang efektif dan efisien agar diperoleh hasil yang ekonomis, digunakan perbandingan perhitungan pada ketiga metode tersebut. Respons struktural yang ditinjau adalah regangan vertikal dan regangan horizontal yang dapat menganalisis kerusakan fatik dan kerusakan rutting pada perkerasan lentur. Program KENPAVE juga membantu dalam perhitungan desain perkerasan lentur dan parameter lainnya.
\end{abstract}

Kata kunci: Jalan Pantura; perkerasan lentur; desain ulang; KENPAVE

\section{PENDAHULUAN}

Jalan raya merupakan jalur - jalur tanah di atas permukaan bumi yang dibuat oleh manusia dengan macam-macam ukuran, bentuk dan jenis konstruksinya sehingga dapat digunakan untuk menyalurkan lalu lintas orang, hewan, benda dan kendaraan yang mengangkut barang dari suatu tempat ke tempat lainnya dengan praktis dan cepat. Jalan yang terus menerus dipakai dapat menyebabkan kerusakan oleh sebab itu, jalan memerlukan pemeliharaan setiap per satuan waktu dalam tahun. Kerusakan jalan dapat menyebabkan terhambatnya pergerakan lalu lintas dan mengganggu aktivitas ekonomi pada manusia. 
Jalan Pantura merupakan jalan utama di Pulau Jawa yang lebih dikenal dengan jalan Nasional I, jaringan jalan ini sejajar dengan garis pantai pulau lokasi tersebut kemudian, jalur ini menghubungkan kegiatan nasional antarpusat, jalan Pantura setiap harinya dilewati banyak kendaraan terutama menjelang hari Raya Lebaran.

Penelitian ini dilakukan untuk mendesain ulang tebal perkerasan lentur pada jalan Pantura ruas Tangerang-Serang. Dalam mendesain ulang perkerasan tersebut digunakan perhitungan melalui ketiga metode yaitu, metode 2002, 2013, dan 2017. Selain itu, diperlukan juga perhitungan mengenai respons strukural perkerasan lentur dan kerusakan yang terjadi pada perkerasan tersebut akibat pembebanan berulang. Ada dua cara dalam perhitungan tersebut yaitu, cara manual dan bantuan program KENPAVE sesuai dengan data parameter yang ditentukan.

Program KENPAVE dapat menganalisis perkerasan lentur dengan fleksibel dan lebih mudah daripada program yang lain, dalam menjalankan program KENPAVE adalah memasukkan data-data yang diperlukan yaitu sifat karakteristik perkerasan dan material seperti modulus, poisson ratio setiap lapisan, beban roda, tekanan ban, dan koordinat dimana tegangan dan regangan yang diperlukan untuk kita dapatkan.

Berdasarkan latar belakang tersebut, penelitian ini akan membandingkan hasil perhitungan tebal perkerasan dari tiga metode yaitu, Pedoman Perencanaan Tebal Perkerasan Lentur 2002, Manual Desain Perkerasan Jalan 2013, dan Manual Desain Perkerasan Jalan 2017. Setelah menghitung tebal perencanaan perkerasan masing-masing metode, selanjutnya adalah membandingkan hasil perhitungan repetisi beban dengan kerusakan fatik (Nf) dan kerusakan rutting $(\mathrm{Nd})$ dari tiga metode tersebut melalui program KENPAVE.

Batasan masalah pada penelitian ini:

1. Pada desain dengan metode 2002, semua jenis fondasi (berbutir, bersemen, dan beraspal) akan digunakan.

2. Pada desain dengan metode 2013 dan 2017, semua jenis fondasi (berbutir dan cement treated base) akan digunakan.

3. Data volume lalu-lintas didapat dari Kementerian PUPR pada tahun 2019.

4. Respons struktural yang ditinjau adalah regangan horizontal dan regangan vertikal.

5. Prediksi kerusakan yang ditinjau adalah kerusakan fatik dan kerusakan rutting.

6. Analisis respons struktural menggunakan bantuan program KENPAVE dengan simulasi beban berupa sumbu tunggal standar.

Berdasarkan masalah yang dirumuskan pada rumusan masalah, maka tujuan dari penelitian ini adalah:

1. Mendesain ulang perkerasan lentur pada jalan Pantura ruas Tangerang-Serang berdasarkan metode 2002, 2013, dan 2017.

2. Menganalisis respons struktural perkerasan lentur hasil perancangan.

3. Menganalisis prediksi kerusakan perkerasan lentur hasil perancangan

\section{Perkerasan lentur}

Menurut Sukirman (1992), perkerasan lentur terdiri dari lapisan-lapisan yang dipadatkan di atas tanah dasar, bahan pengikat perkerasan ini adalah aspal. Lapisan-lapisan tersebut berfungsi menerima beban lalu-lintas dan menyebakan ke lapisan di bawahnya. Komponen perkerasan lentur (flexible pavement) terdiri atas tanah dasar, lapis pondasi bawah, lapis pondasi atas, dan lapis permukaan.

\section{Golongan kendaraan}

Kendaraan rencana merupakan wakil dari suatu kelompok kendaraan tersebut yang digunakan untuk merencanakan bagian-bagian dari jalan raya. Dalam perencanaan geometrik jalan, lebar lajur yang diperlukan tergantung dari ukuran lebar kendaraan rencana, hal lain yang perlu diperhatikan adalah kemampuan kendaraan dalam mempengaruhi tingkat kelandaian yang dipilih, dan tinggi tempat duduk pengemudi yang akan mempengaruhi jarak pandangan pengemudi (Silvia Sukirman, 1994). Terdapat delapan jenis golongan kendaraan yang dikelompokkan berdasarkan jenis kendaraan yang ditunjukkan pada Tabel 1. 
Tabel 1. Golongan dan kelompok jenis kendaraan (Sumber: Pd. T-19-2004-B)

\begin{tabular}{cc}
\hline Golongan & Kelompok jenis kendaraan \\
\hline Golongan 1 & Sepeda motor, Kendaraan roda-3 \\
Golongan 2 & Sedan, jeep, station wagon \\
Golongan 3 & Angkutan penumpang sedang \\
Golongan 4 & Pick up, micro truk dan mobil hantaran \\
Golongan 5a & Bus kecil \\
Golongan $5 \mathrm{~b}$ & Bus besar \\
Golongan $6 \mathrm{a}$ & Truk ringan 2 sumbu \\
Golongan $6 \mathrm{~b}$ & Truk sedang 2 sumbu \\
Golongan 7a & Truk 3 sumbu \\
Golongan 7b & Truk gandengan \\
Golongan 7c & Truk semitrailer \\
Golongan 8 & Kendaraan tidak bermotor \\
\hline
\end{tabular}

\section{Metode bina marga 2002}

Pedoman perencanaan tebal perkerasan lentur Pt T-01-2002-B merupakan pedoman yang dikeluarkan oleh Bina marga, pedoman ini mengacu pada AASHTO Guide for Design of Pavement Structures, 1993. Perencanaan tebal perkerasan pada metode ini mengacu kepada kekuatan masing-masing lapisan.

\section{Metode bina marga 2013}

Metode Bina Marga 2013 ini melengkapi pedoman desain perkerasan Pd T-01-2002-B dan Pd T-14-2003. Dalam perencanaan tebal lapisan perkerasan perlu adanya umur rencana jalan, umur rencana adalah jumlah waktu per tahun semenjak jalan tersebut dibuka sampai saat waktu diperlukan tambahan lapisan baru atau perlu perbaikan yang berat.

\section{Metode bina marga 2017}

Manual Desain Perkerasan Jalan (MDP) 2017 berisi ketentuan teknis untuk perancangan desain perkerasan jalan. Ditetapkan oleh Dirjen Bina Marga pada tanggal 22 Juni 2017 melalui SE No 04/SE/Db/2017 untuk merevisi SE No 08/SE/Db/2013 tentang MDP 2013.

\section{Metode mekanisik-empiris}

Komponen mekanistik yaitu, menjelaskan fenomena-fenomena yang mengacu pada penyebab-penyebab perubahan fisis saja. Dalam perencanaan perkerasan, fenomena-fenomena tersebut adalah tegangan, regangan, dan lendutan (deflection) di dalam struktur perkerasan, dan penyebab perubahan fisis itu adalah beban-beban dan jenis material (material properties) dari struktur perkerasan.

Metode mekanistik-empiris merupakan metode baru yang dikembangkan untuk memprediksi kerusakan jalan di Indonesia. Tahap pertama, menghitung respon perkerasan yang berupa tegangan, regangan, dan lendutan kritis setiap lapisan perkerasan dengan menggunakan analisis metode mekanistik yang berdasarkan prinsip-prinsip teori elastis. Tahap kedua, dengan meramal performa keadaan struktur dan fungsi perkerasan di masa depan yang merupakan fungsi beban lalu lintas dan pengaruh lingkungan yang ada di sekitarnya (Suparma, 2014).

\section{Sistem berlapis (layered system) perkerasan lentur}

Sistem Multilapis Elastis adalah salah satu penyelesaian analisis pada metode mekanistik. Sistem struktur lapisan banyak ini berkenaan dengan tegangan, regangan, dan lendutan berupa respon dari perkerasan terhadap beban roda kendaran yang melintas di atasnya. Pada multi-layered elastic system, digunakan beberapa asumsi dalam menghitung respons struktur, antara lain: sifat bahan dari setiap lapisan perkerasan dianggap homogen, setiap lapisan mempunyai batas ketebalan, tiap lapisan dianggap isotropik, friksi yang terjadi di antara lapisan yaitu di interface, Sifat bahan diwakili oleh dua parameter struktural, yaitu modulus resilient (E atau MR) dan Rasio Poisson ( $\mu$ ) (Yoder dan Witczak, 1975). Berikut dapat dilihat gambar sistem lapis banyak yang ditunjukkan pada Gambar 1. 


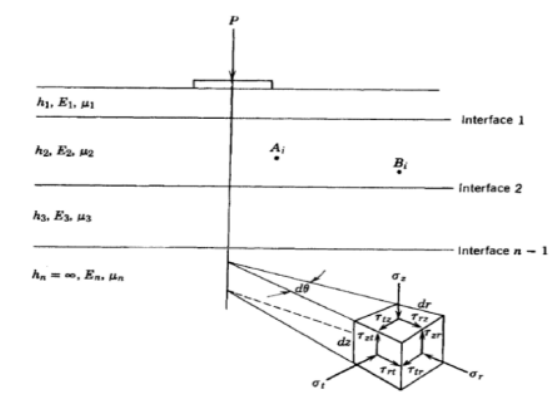

Gambar 1. Sistem lapis banyak (Sumber: Yoder dan Witczak, 1975)

\section{Sistem tiga lapis pada perkerasan lentur}

Menurut Yodzer dan Witczak (1975), dapat dilihat tegangan - tegangan sistem tiga lapis pada axis simetri yang ditunjukkan pada Gambar 2.
a. $\quad$ zz1 : tegangan vertikal interface 1
b. $\sigma z 2$ : tegangan vertikal interface 2
c. $\sigma \mathrm{r} 1$ : tegangan horisontal pada lapisan 1 bagian bawah
d. $\sigma \mathrm{r} 2$ : tegangan horisontal pada lapisan 2 bagian bawah
e. $\sigma r 3$ : tegangan horisontal pada lapisan 3 bagian atas

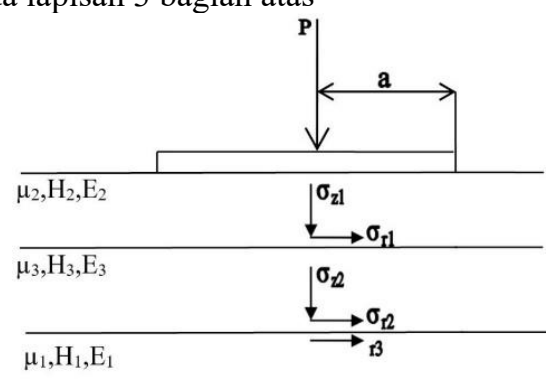

Gambar 2. Tegangan sistem tiga lapis (Yodzer dan Witczak, 1975)

\section{Respons struktural}

Respons Struktural dipengaruhi oleh beban lalu lintas yang bergerak, redaman dan sentuhan roda pada permukaan perkerasan jalan. Bahan perkerasan umumnya anisotropis dan butirannya heterogen yang perilakunya dapat dimodelkan secara liquid newtonian dan solid hookean (Ullidtz, 1998). Berikut dapat dilihat respons titik lapisan perkerasan lentur yang ditunjukkan pada Gambar 3.

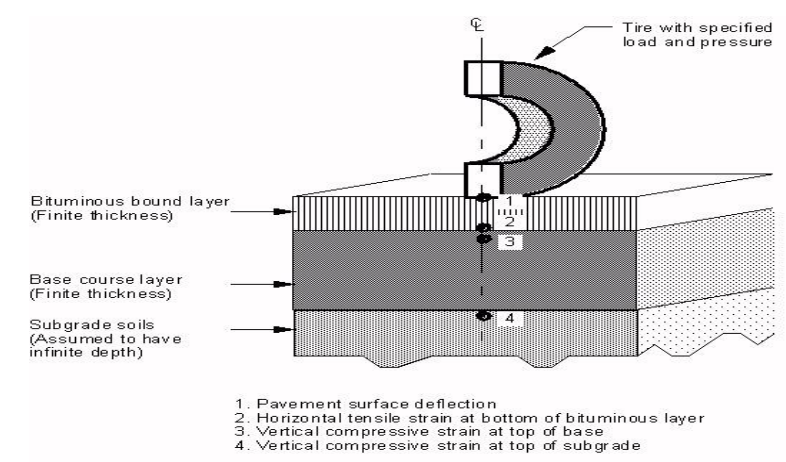

Gambar 3. Respons titik lapisan perkerasan lentur (Sumber: Pavement Interactive, 2008)

a. Tipe kerusakan perkerasan lentur

1. Repetisi izin terhadap kerusakan fatik (fatigue failure), rumus dilihat pada Persamaan 1. 


$$
\mathrm{Nf}=0,0796\left(\frac{1}{\varepsilon \mathrm{t}}\right)^{3.291}\left(\frac{1}{E 1}\right)^{0.854}
$$

$\mathrm{Nf}=$ repetisi beban dalam menghindari fatik, $\mathrm{Et}$ = regangan tarik bagian bawah lapis permukaan, dan $\mathrm{E}=$ modulus elastis lapis permukaan

2. Repetisi izin terhadap kerusakan retak alur (rutting), rumus dilihat pada Persamaan 2.

$$
\mathrm{Nd}=1,365 \times 10^{-9}\left(\frac{1}{\varepsilon \mathrm{c}}\right)^{4.477}
$$

$\mathrm{Nd}=$ repetisi beban dalam menghindari rutting, dan $\mathrm{Ec}=$ regangan tekan bagian bawah lapis pondasi bawah

\section{Program KENPAVE}

KENPAVE merupakan perangkat lunak yang menggabungkan perkakas fleksibel KENOLF dan perkerasan kaku KENSLAB, memungkinkan untuk pengguna elastis linier, nonlinier dan sifat viskoelastik bahan untuk lapisan yang berbeda (Loulizi dkk., 2006). Sebelum KENPAVE dibuat, terdapat empat program grafis secara terpisah yakni LAYEINP, KENLAYE, SLABNINP, KENSLAB.

KENPAVE adalah software desain perencanaan perkerasan yang dikembangkan oleh Dr. Yang H Huang, P.E. Professor Emeritus of Civil Engineering University of Kentucky. Software ini menggunakan bahasa pemrograman Visual Basic dan dijalankan dengan versi windows 95 atau diatasnya (Huang, 2004).

\section{METODE PENELITIAN}

Penelitian ini dimulai dengan mendapatkan data primer berupa volume lalu lintas Jalan Pantura ruas TangerangSerang tahun 2019 dari Kementerian PUPR. Berikut bagan alir ditunjukkan pada Gambar 4.

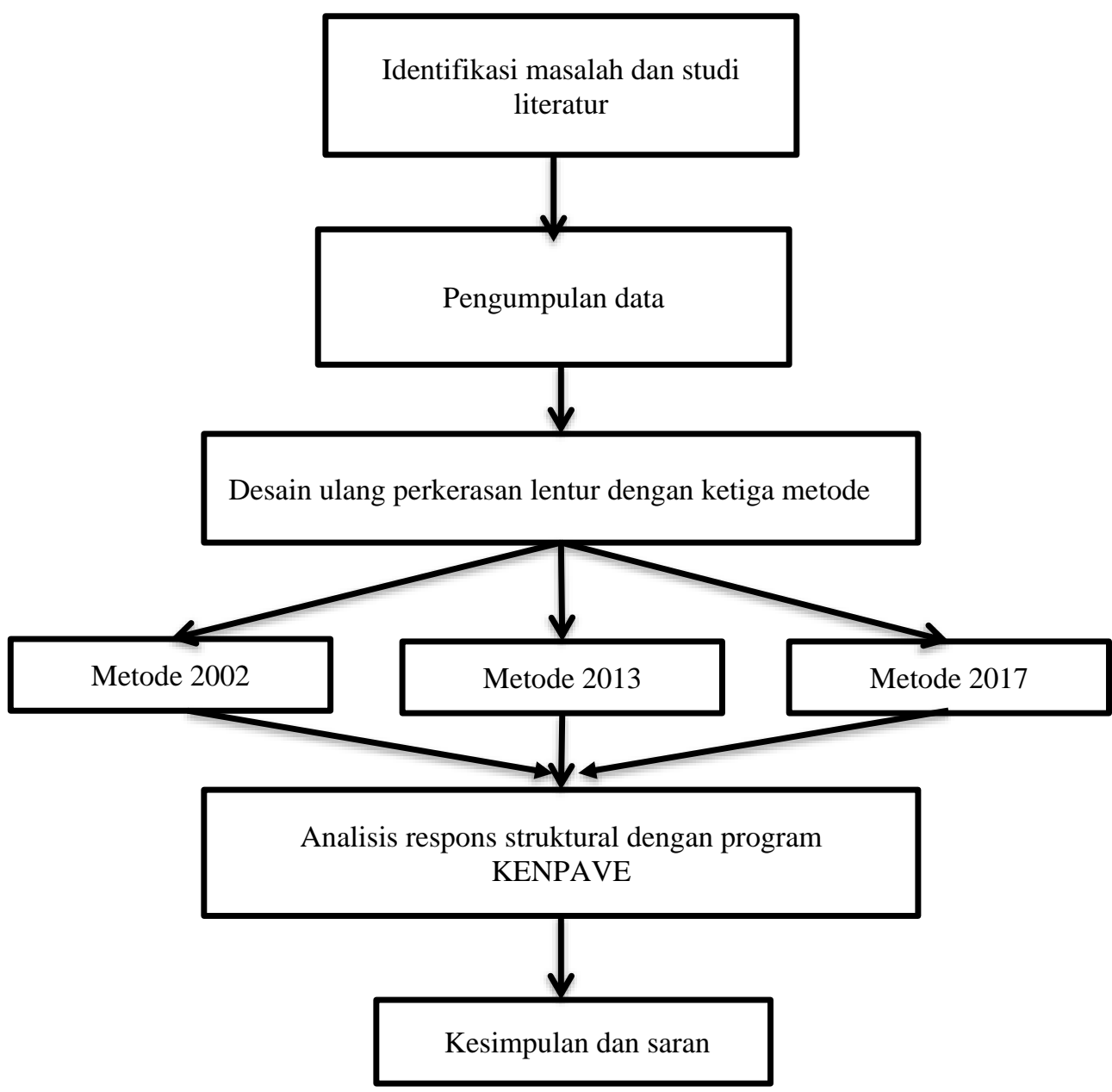

Gambar 4. Bagan alir penelitian 


\section{HASIL DAN PEMBAHASAN}

\section{Tanah dasar}

Nilai CBR pada ruas jalan Pantura ruas Tangerang-Serang sebesar $4 \%$.

\section{Pertumbuhan lalu-lintas}

Pada jalan Pantura ruas Tangerang-Serang dengan kelas jalan arteri primer digunakan faktor pertumbuhan lalu-lintas untuk metode 2002 dan 2017 adalah $\mathrm{i}=4,8 \%$, sementara untuk metode 2013 digunakan $\mathrm{i}=5 \%$.

\section{Vehicle damage vector (VDF)}

NIlai VDF metode 2002 berbeda dengan metode 2013 dan 2017. Nilai VDF metode 2013 dan 2017 sudah disediakan dalam pedoman berupa tabel. Sementara metode 2002 belum disediakan nilai VDF sehingga perlu menghitung dahulu beban kendaraan per golongan, perhitungan tersebut menggunakan referensi penelitian Tajudin dan Priyatna (2019).

\section{Perbandingan hasil perhitungan cumulative single axle (CESA)}

Berikut dapat dilihat perbandingan nilai CESA yang ditunjukkan pada Tabel 2. Nilai CESA terbesar ada pada metode 2013, dan nilai CESA terkecil ada pada metode 2002.

Tabel 2. Perbandingan cumulative single axle (CESA) antar metode

\begin{tabular}{cccc}
\hline & 2002 & 2013 & 2017 \\
\cline { 2 - 3 } TOTAL CESA & $43.785 .775,21$ & $65.739 .276,45$ & $49.109 .453,74$ \\
\hline
\end{tabular}

\section{Perbandingan modulus antar metode}

Berikut dapat dilihat perbandingan modulus antar metode yang ditunjukkan pada Tabel 3. Pedoman metode bina marga 2002 nilai modulus untuk masing-masing lapisan diperoleh dengan cara menarik grafik secara manual, serta modulus tipikal untuk lapis permukaan ditentukan oleh perencana sendiri, dilakukan dengan cermat dan mempertimbangkan aspek seperti volume lalu lintas, umur rencana, dan perencanaan biaya. Sedangkan pada pedoman metode bina marga 2013 dan 2017 telah disajikan tabel modulus sesuai ketetapan angka yang bisa digunakan sesuai masing-masing jenis lapis perkerasan.

Tabel 3. Perbandingan modulus tipikal antar metode

\begin{tabular}{|c|c|c|c|c|c|c|c|c|c|c|c|}
\hline \multicolumn{4}{|c|}{$2002(\mathrm{MPa})$} & \multicolumn{4}{|c|}{$2013(\mathrm{MPa})$} & \multicolumn{4}{|c|}{$2017(\mathrm{MPa})$} \\
\hline $\begin{array}{c}\text { Tipe } \\
\text { Pondasi }\end{array}$ & Granular & Beraspal & Bersemen & $\begin{array}{c}\text { Tipe } \\
\text { Pondasi }\end{array}$ & CTB & $\begin{array}{c}\text { Tipe } \\
\text { Pondasi }\end{array}$ & Berbutir & $\begin{array}{c}\text { Tipe } \\
\text { Pondasi }\end{array}$ & CTB & $\begin{array}{c}\text { Tipe } \\
\text { Pondasi }\end{array}$ & Berbutir \\
\hline LP & 2586 & 2586 & 2586 & $\mathrm{AC} W \mathrm{C}$ & 1100 & $\mathrm{AC} W \mathrm{C}$ & 1100 & $\mathrm{AC} W \mathrm{C}$ & 1100 & $\mathrm{AC} W \mathrm{C}$ & 1100 \\
\hline LPA & 207 & 1600 & 4827 & $\mathrm{AC} B \mathrm{C}$ & 1200 & $\begin{array}{c}\mathrm{AC} \\
\text { Binder }\end{array}$ & 1200 & $\mathrm{AC} B \mathrm{BC}$ & 1200 & $\mathrm{AC} B \mathrm{C}$ & 1200 \\
\hline LPB & 128 & 128 & 128 & СТВ & 500 & $\begin{array}{l}\text { AC } \\
\text { Base }\end{array}$ & 1600 & $\begin{array}{c}\text { AC } \\
\text { Base }\end{array}$ & 1600 & $\begin{array}{c}\text { AC } \\
\text { Base }\end{array}$ & 1600 \\
\hline & & & & $\begin{array}{c}\text { LPA } \\
\text { Kelas A }\end{array}$ & 150 & $\begin{array}{c}\text { LPA } \\
\text { Kelas A }\end{array}$ & 150 & CTB & 500 & $\begin{array}{c}\text { LPA } \\
\text { Kelas A }\end{array}$ & 150 \\
\hline & & & & & & & & $\begin{array}{c}\text { LPA } \\
\text { Kelas A }\end{array}$ & 150 & & \\
\hline
\end{tabular}

\section{Perbandingan tebal perkerasan antar metode}

Berikut dapat dilihat hasil akhir tebal perkerasan lentur metode bina marga 2002 yang ditunjukkan pada Tabel 4.

Tabel 4. Hasil akhir tebal perkerasan lentur metode bina marga 2002

\begin{tabular}{cccc} 
& \multicolumn{3}{c}{ Tipe Fondasi } \\
Granular & $\begin{array}{c}\text { Beraspal } \\
(\mathrm{mm})\end{array}$ & $\begin{array}{c}\text { Bersemen } \\
(\mathrm{mm})\end{array}$ \\
\hline Lapis Permukaan & 260 & 130 & 110 \\
Lapis Pondasi Atas & 160 & 280 & 460 \\
Lapis Pondasi Bawah & 160 & 260 & 230 \\
\hline
\end{tabular}

Berikut dapat dilihat hasil akhir tebal perkerasan lentur metode bina marga 2013 yang ditunjukkan pada Tabel 5. 
Tabel 5. Hasil akhir tebal perkerasan lentur metode bina marga 2013

\begin{tabular}{cccc}
\hline Jenis Perkerasan & $\begin{array}{c}\text { Lapis Fondasi CTB } \\
(\mathrm{mm})\end{array}$ & Jenis Perkerasan & $\begin{array}{c}\text { Lapis Fondasi Berbutir } \\
(\mathrm{mm})\end{array}$ \\
\hline AC WC & 40 & AC WC & 40 \\
AC BC & 185 & AC BINDER & 60 \\
CTB & 150 & AC BASE & 210 \\
LPA KELAS A & 150 & LPA KELAS A & 300 \\
PERBAIKAN & 200 & PERBAIKAN & 200 \\
\hline
\end{tabular}

Berikut dapat dilihat hasil akhir tebal perkerasan lentur metode bina marga 2017 yang ditunjukkan pada Tabel 6.

Tabel 6. Hasil akhir tebal perkerasan lentur metode bina marga 2017

\begin{tabular}{cccc}
\hline Jenis Perkerasan & $\begin{array}{c}\text { Lapis Fondasi CTB } \\
(\mathrm{mm})\end{array}$ & Jenis Perkerasan & $\begin{array}{c}\text { Lapis Fondasi Berbutir } \\
(\mathrm{mm})\end{array}$ \\
\hline AC WC & 40 & AC WC & 40 \\
AC BC & 60 & AC BC & 60 \\
AC BASE & 100 & AC BASE & 180 \\
CTB & 150 & LPA KELAS A & 300 \\
LPA KELAS A & 150 & PERBAIKAN & 200 \\
PERBAIKAN & 200 & & \\
\hline
\end{tabular}

Melalui Tabel 4, 5, dan 6 dapat dilihat bahwa, metode 2002 terdapat 3 tipe lapisan perkerasan yaitu, tipe 1 terdiri dari lapis permukaan (AC) + Granular + Granular, tipe 2 terdiri dari lapis permukaan (AC) + AC Base + Granular, dan tipe 3 terdiri dari lapis permukaan $(\mathrm{AC})+\mathrm{CTB}+$ Granular. Dari segi bahan penyusun lapis pondasi perkerasan metode 2002 terdiri dari bahan granular, beraspal, dan bersemen. Desain metode 2002 terdiri dari 3 lapis perkerasan. Pada metode 2013 digunakan dua jenis lapis pondasi yaitu, lapis pondasi bersemen (CTB) dan lapis pondasi berbutir, metode 2013 terdiri dari 5 lapis perkerasan dan metode 2017 terdiri dari 6 lapis perkerasan untuk bahan CTB dan 5 lapis perkerasan untuk bahan berbutir. Pada perbandingan perhitungan dari ketiga metode, lapis pondasi dengan tipe granular metode 2002, lapis permukaanya lebih tebal dibandingkan lapis pondasi dibawahnya hal ini karena lapis permukaan langsung bersentuhan dengan beban roda sehingga rentan mengalami kerusakan pada tipe tersebut, jika diurutkan tebal lapis permukaan yang dibutuhkan dari yang terkecil hingga terbesar maka (1) lapis pondasi bersemen, (2) lapis pondasi beraspal, dan (3) lapis pondasi granular. Sementara untuk metode 2013 dan 2017 tersusun dari banyak lapisan dan jenis material sehingga lapis permukaan yang dibutuhkan tidak setebal seperti lapis pondasi dibawahnya serta didapatkan lapis perkerasan yang optimal.

\section{Perbandingan Nilai Et dan Ec pada Metode 2002, 2013, dan 2017}

Berikut dapat dilihat hasil nilai Et dan Ec pada metode 2002,2013, dan 2017 yang ditunjukkan pada Tabel 7.

Tabel 7. Hasil nilai Et dan Ec pada metode 2002, 2013, dan 2017

\begin{tabular}{lcccc}
\hline & Metode & Tipe & Et & Ec \\
\hline \multirow{2}{*}{2002} & AC $(\mathrm{E}=375.000 \mathrm{psi})$ & Granular & $1,202 \mathrm{E}-04$ & $2,741 \mathrm{E}-04$ \\
& & Beraspal & $5,067 \mathrm{E}-05$ & $1,613 \mathrm{E}-04$ \\
2013 & - & Bersemen & $2,403 \mathrm{E}-06$ & $7,547 \mathrm{E}-05$ \\
& & Lapis Pondasi CTB & $1,212 \mathrm{E}-04$ & $2,817 \mathrm{E}-04$ \\
2017 & - & Lapis Pondasi CTB & $1,351 \mathrm{E}-04$ & $2,265 \mathrm{E}-04$ \\
& & Lapis Pondasi Berbutir & $1,253 \mathrm{E}-04$ & $3,016 \mathrm{E}-04$ \\
\hline
\end{tabular}

Melalui Tabel 7 dapat dilihat bahwa lapis pondasi berbutir metode 2017 memiliki nilai Et terbesar yaitu 1,548E-04 dan metode 2002 tipe bersemen memiliki nilai Et terkecil yaitu 2,403E-06. Lapis pondasi CTB metode 2017 memiliki nilai Ec terbesar yaitu 3,016E-04 dan metode 2002 tipe bersemen memiliki nilai Ec terkecil yaitu 7,547E05, artinya metode 2002 bersemen dapat menahan beban lalu lintas lebih besar daripada metode 2013 dan 2017. Sementara untuk nilai Ec, artinya metode 2002 bersemen dapat menahan beban lalu lintas lebih besar daripada 
metode 2013 dan 2017 juga. Dapat disimpulkan bahwa hasil perhitungan regangan horizontal (Et) dan regangan vertikal (Ec) pada metode 2002 lebih baik dibandingkan metode 2013 dan 2017.

\section{Perbandingan nilai Nf dan Nd pada Metode 2002,2013, dan 2017}

Berikut dapat dilihat hasil perbandingan nilai Nf dan Nd antar metode yang ditunjukkan pada Tabel 8.

Tabel 8. Perbandingan nilai Nf dan Nd antar metode

\begin{tabular}{cccccc}
\hline \multicolumn{2}{c}{ Metode } & Tipe & W18 per hari & $\mathrm{Nf}$ & $\mathrm{Nd}$ \\
\hline \multirow{2}{*}{2002} & AC $(\mathrm{E}=$ & Granular & 9263,23298 & 2.116 .229 & 12.095 .224 \\
& $375.000 \mathrm{psi})$ & Beraspal & 9263,23298 & 36.323 .951 & 129.883 .382 \\
\multirow{2}{*}{2013} & & Bersemen & 9263,23298 & 826.927 .912 .361 & 3.893 .470 .482 \\
\multirow{2}{*}{2017} & - & Lapis Pondasi CTB & $13.617,3$ & 4.273 .233 & 10.701 .310 \\
& & Lapis Pondasi CTB & $13.617,3$ & 2.989 .351 & 28.411 .378 \\
& & Lapis Pondasi Berbutir & $10.389,5$ & 3.830 .070 & 7.883 .491 \\
\hline
\end{tabular}

Melalui Tabel 8, dapat dilihat bahwa secara keseluruhan metode 2002 AC ( $E=375.000$ psi) dengan lapis pondasi atas bersemen memiliki nilai Nf terbesar dari semua metode, sedangkan metode 2017 lapis pondasi atas berbutir memiliki nilai Nf terkecil dari semua metode. Secara keseluruhan metode 2002 AC (E=375.000 psi) dengan lapis pondasi bersemen memiliki nilai Nd terbesar dari semua metode, sedangkan metode 2017 dengan lapis pondasi CTB memiliki nilai Nd terkecil dari semua metode. Dari hasil tersebut, dapat disimpulkan bahwa metode 2002 AC ( $\mathrm{E}=375.000 \mathrm{psi}$ ) dengan lapis pondasi bersemen memiliki Nf dan Nd terbesar dimana memiliki repetisi izin yang tinggi terhadap kerusakan fatik dan rutting, yang artinya dimana berarti perkerasan bagus karna bisa menahan semakin banyak kendaraan sebelum timbulnya rusak fatik dan rutting. Dapat dilihat juga, bahwa Nf dan Nd dari keseluruhan metode telah memenuhi/melewati repetisi beban/aktual, sehingga desain dapat dipakai untuk waktu yang lama bahkan melebihi umur rencana itu sendiri, kekurangannya jika dilihat besaran angka Nf dan Nd metode 2002 bersemen terhadap repetisi izinnya terlampau tinggi hal ini yang dinamakan overdesign.

\section{KESIMPULAN DAN SARAN}

\section{Kesimpulan}

Berdasarkan penelitian mengenai desain ulang dan analisis program KENPAVE dan perhitungan manual perkerasan lentur menggunakan metode bina marga 2002, 2013, dan 2017, dapat disimpulkan bahwa:

1. Pada pehitungan jumlah kumulatif beban standar ekivalen selama umur rencana (CESA), metode 2013 didapatkan nilai CESA yang paling besar daripada metode 2002 dan 2017.

2. Dalam metode 2002 digunakan tiga jenis lapis pondasi yang terdiri dari granular, beraspal, dan bersemen. Sementara, pada metode 2003 dan 2017 terdiri dari lapis pondasi bersemen dan berbutir. Banyak lapisan perkerasan pada metode 2002 lebih sedikit dibandingkan metode 2013 dan 2017, yaitu empat lapisan pada metode 2002 yang sudah termasuk tanah dasar dan enam hingga tujuh lapisan pada metode 2013 dan 2017 yang sudah termasuk lapis perbaikan tanah dan tanah dasar.

3. Besaran nilai modulus tipikal lapis permukaan pada metode 2002 cenderung lebih besar karena pada metode ini belum disediakan tabel modulus seperti pada metode 2013 dan 2017, sehingga besarannya ditentukan secara manual dengan mempertimbangkan parameter-parameter didalamnya seperti biaya dalam perencanaan, umur rencana perkerasan, dan lainnya.

4. Berdasarkan perbandingan perhitungan tebal perkerasan, metode 2002 memiliki lapis permukaan paling tebal dengan komposisi hanya empat layer yang sudah termasuk tanah dasar, hal ini terlihat tidak optimal dibandingkan tebal perkerasan 2013 dan 2017 yang mana tebal lapis permukaan terbagi menjadi dua jenis dan terdapat enam hingga tujuh layer, penyaluran beban kendaraan dari atas sampai ke tanah dasar juga lebih optimal.

5. Berdasarkan perhitungan kerusakan fatik (Nf) dan kerusakan rutting $(\mathrm{Nd})$, dari ketiga metode tersebut, dapat dilihat desain metode 2002 overdesign hal ini ditandai dengan besaran perhitungan $\mathrm{Nf}$ dan $\mathrm{Nd}$ menggunakan rumus, hasilnya jauh lebih besar dari repetisi beban yang diizinkan, terlihat desain paling baik dari ketiga metode tersebut yaitu, metode 2017. 


\section{Saran}

Berdasarkan penelitian mengenai desain ulang dan analisis program KENPAVE dan perhitungan manual perkerasan lentur menggunakan metode bina marga 2002, 2013, dan 2017 terdapat beberapa kekurangan. Berikut merupakan saran untuk penelitian selanjutnya, yaitu:

1. Perlu penelitian lebih lanjut mengenai studi kasus ruas Jalan Pantura lain atau jalan tol dengan beragam tipe jalan yang terbagi dan tidak terbagi, serta volume lalu-lintas yang lebih beragam.

2. Perlu penelitian lebih lanjut mengenai macam-macam kerusakan yang terjadi pada perkerasan lentur selain kerusakan fatik dan kerusakan alur.

3. Perlu penelitian lebih lanjut mengenai respons struktural perkerasan akibat beban berulang dan pengaruhnya terhadap defleksi permukaan jalan.

\section{DAFTAR PUSTAKA}

A.N. Tajudin dan R. Priyatna. "Effect of Axle and Tire Configurations on Flexible Pavement." 508.1 (2019): 012004.

-, Pedoman Perencanaan Tebal Perkerasan Lentur Pt. T-01-B. Jakarta: Departemen Pemukiman dan Prasarana Wilayah, 2002.

Huang, Yang H. Pavement Analysis and Design 2nd Ed. New Jersey: Pearson Education Inc., 2004.

Loulizi, A., I. L Al-Qadi dan M. Elseifi. "Difference Between In-Situ Flexible Pavement Measured and Calculated Stresses and Strains." Journal of Transportation Engineering (2006): 574-579.

Pavement Interactive. www.pavementinteractive.org/reference-desk/design/structural-design/flexible-pavementmechanistic-models/. March 2008. 20 September 2020.

Sukirman, Silvia. Dasar-dasar Perencanaan Geometrik Jalan. Bandung: Nova, 1994.

Sukirman, Silvia. Perkerasan Lentur Jalan Raya. Bandung: Nova, 1992.

Suparma, Latif Budi. Prediksi Nilai Kerusakan Perkerasan Lentur dengan Metode Mekanistik-Empirik (Studi Kasus: Rekonstruksi Jl. Arteri Selatan). Yogyakarta: Universitas Gadjah Mada, 2014.

Ullidtz, P. Modelling Flexible Pavement Response and Performance. Denmark: Technical University of Denmark, 1998.

Yoder, E. J dan M. W Witczak. Principles of Pavement Design 2nd Edition. New York: A Wiley-Interscience Publication, 1975. 
